\title{
¿Por qué murió Jesús? Iniciación a los Evangelios. Volumen III: lectura del protagonista
}

\author{
Mike van Treek \\ PONTIFICIA UNIVERSIDAD CATÓLICA DE CHILE \\ FACULTAD DE TEOLOGÍA
}

El libro puede ser presentado en cuatro partes ${ }^{1}$ : (1) los principios de lectura propuestos por el autor; (2) la articulación del libro; (3) la respuesta a la pregunta por la muerte de Jesús; (4) valoración teológica de la respuesta a la pregunta por el sentido.

\section{Principios de lectura propuestos por el autor}

El autor expresa su gran meta: "Ayudar a los lectores de hoy a comprender la riqueza del texto de los Evangelios" (Introducción). Esta afirmación encierra algunas riquezas que el texto va desplegando; veamos algunas de ellas. El libro es un facilitador, no un contenedor de respuestas ya hechas y listas para usar. En 699 páginas caben muchos datos, pero el lector no encuentra todo hecho. Se le facilita el trabajo y al mismo tiempo se le responsabiliza de él. Comprender los evangelios significa aceptar la invitación de entrar en el mundo que despliegan frente al lector: "El mundo del Jesús predicador de salvación, anunciador de la buena noticia (el "evangelio") del Reinado de Dios que está a punto de irrumpir en nuestra historia" (Introducción). El lenguaje usado por los evangelios se orienta no a informar sino a crear ese mundo habitable por el lector (Introducción). Encontrarse con el Jesús de los evangelios implica para el lector reconocer que -como toda la Biblia- son textos literarios y que se expresan en diversos niveles del lenguaje. Silva usa un cierto instrumental en ello y divide entre denotación y connotación. Hay otros posibles, él se mantiene fiel a ese y saca buen provecho. El Jesús de los evangelios es lo que se quiere comprender. Silva se sitúa aquí entre dos tendencias de la teología y de la exégesis. Por una parte, se ha tratado de reducir a Jesús al "Cristo de la fe" a unas cuantas verdades seguras sobre Jesús formuladas en diversas instancias magisteriales. Por otra parte, se ha tratado de encerrar a Jesús en el "Jesús de la historia", es decir en una reconstrucción de Jesús según los métodos de la ciencia histórica moderna. Si ambos registros

1 Esta reseña reproduce con algunas modificaciones mi presentación del libro durante el lanzamiento en la Facultad de Teología de la Pontificia Universidad Católica de Chile, el 29 de septiembre de 2009. 
tienen razón para sustentarse, han puesto a la sombra lo único certero: el texto. De ahí la importancia para el autor de recuperar al Jesús que ha sido tejido literariamente por los evangelistas. Se propone una hipótesis que explica el por qué de la sombra proyectada sobre el Jesús de los Evangelios: "Ambas búsquedas, tanto la del Jesús histórico como la del Cristo de la fe, me parece que han estado motivadas por el deseo de 'fijar' una imagen definitiva de Jesús que lo sustraiga al incómodo flujo de la historia" (Introducción).

\section{La articulación del libro}

El libro se estructura en cuatro partes principales emplazadas entre una introducción metodológica y un final en la cual sintetiza los datos del libro para dar respuesta a la pregunta que motiva la escritura de todo este proyecto editorial: el sentido de la muerte de Jesús. El lector va encontrando que la respuesta tiene una estructura "multicapa" compleja.

En la primera parte - hechos biográficos- explora la vida de Jesús tal y cual la narran los 4 evangelistas canónicos centrándose en la cuestión de su ministerio público. Ahí asoma ya una primera capa de la respuesta a la pregunta por el sentido de la muerte de Jesús. Retomando la respuesta del volumen primero realiza algo nuevo: decide explorar la muerte de Jesús poniendo atención al proceso que el personaje mismo vive frente a ella, esa es la primera capa de la respuesta. La opción me parece que ha sido lograda con atractiva belleza teológica; luego diré por qué.

En la segunda parte -Jesús, uno de nosotros- Silva se esfuerza por analizar el personaje de Jesús según el mismo modelo con que se abordó la cuestión de la cultura en el volumen segundo (Toda cultura enfrenta cinco diferentes desafíos, a saber, subsistencia, convivencia, autoridad, coexistencia y sentido [cf. Vol. 2. Tercer parte]). Cada uno de los aspectos vistos en Jesús van dando carne a un personaje humano que elabora el sentido de su vida (rescato el espacio dado al cuerpo y a las emociones de Jesús.). En esta parte se delinea una segunda capa de la respuesta: el sentido de la vida de Jesús él solo lo encuentra en relación a la voluntad de su Padre, sentido que Jesús va a elaborar enfrentando el fracaso y la muerte.

En la tercera parte -La causa de Jesús- se logra apreciar la cohesión del personaje. Como el sentido de la vida de Jesús es hacer la voluntad del Padre, la causa de Jesús es la verificación de esa realización histórica. Si las repeticiones con el primer volumen son inevitables (cf. Vol 1. segunda parte), el punto de vista varía bastante. Se enfatiza que el comportamiento de Jesús adquiere coherencia en el horizonte del sentido de su vida. Así, un rasgo sobresale: Jesús es maestro. Esto significa que si él anuncia la inminencia del Reino de su Padre y lo realiza en su comportamiento -sobre todo en la acogida de los marginados- el discipulado es 
el sentido de la vida que todo lector y lectora estamos llamados a descubrir. La capa de la respuesta es que el sentido de la muerte de Jesús es oferta de sentido para la humanidad.

En la cuarta parte - La identidad de Jesús- Silva muestra que seguidores y adversarios se enfrentan en lecturas mutuamente excluyentes y los más cercanos a Jesús frecuentan respuestas algo o bastante inadecuadas. Aquí la pluma del autor añade otra capa a la respuesta a la pregunta por el sentido de la muerte de Jesús. La respuesta auténtica a la identidad de Jesús es que es el mesías escatológico enviado por Dios a su pueblo. Pero el mesianismo de Jesús es escandaloso y no satisface las expectivativas de los seguidores e irrita a los adversarios puesto que Jesús enfatiza los aspectos más incluyentes de la Torah y manifiesta una clara orientación universalista y antisegregacionista.

\section{La respuesta a la pregunta por la muerte de Jesús}

El final. La explicación de la muerte de Jesús es doble: es consecuencia de su actuar histórico y es aceptación de la voluntad del Padre que lo envía. En otras palabras, si su manera de vivir el mesianismo es la causa de su muerte desde el plano objetivo - es condenado por sus adversarios y abandonado por sus seguidores por ello- lo es también desde el plano subjetivo puesto que es la aceptación libre de la muerte por amor al Padre. Entrega total a la causa del Reino, obediencia total a su Padre que reina y reinará en aquél. La muerte de Jesús transforma la muerte en dos sentidos. El primer sentido es que "todos los asesinados en la historia de la humanidad -todos los vencidos y derrotados [...] todos aquéllos cuyas vidas fueron aplastadas [...]- se concentran en Jesús que muere, él los hace suyos, para trasladarlos, con él, al reino de la resurrección" (Capítulo 20: El final). El segundo sentido es que "desde la perspectiva de la muerte como realidad humana, la muerte de Jesús puede ser vista como el acto por el cual Dios hace suya la única realidad que Él no ha creado [...] para transformarla en posibilidad de entregar la vida por amor" (Idem).

De esta forma el teólogo chileno profundiza en la respuesta a la pregunta planteada ya en el primer volumen de la actual trilogía. Lo particular y valioso del recorrido presente es que el autor y el lector de este volumen muestran y aprecian la perspectiva del protagonista -Jesús- y de cómo él puede ir articulando ese sentido para su vida y ofrecerlo a la humanidad.

\section{Valoración teológica de la respuesta a la pregunta por el sentido}

La lectura de este libro ha significado un desafío y una alegría. El desafío no es solo la longitud del escrito, sino que más profundamente la cuestión del diálogo. Desde el principio el libro estimuló mi interés sobre cómo un teólogo del ámbito de la teología fundamental iba a plantear una lectura tan minuciosa de 
un texto bíblico. Descubrí que hay muchos motivos para celebrar esta incursión y que los temores se resolvieron sin violencia. El texto de Silva permite hacer teología bíblica resaltando la unidad de la Biblia.

En este marco, quiero destacar algo que forma parte del núcleo de la propuesta: la cuestión del sentido de la vida de Jesús como la plantea el autor lo conecta con una honda tradición teológica bíblica. El autor explora la forma en que Jesús elabora y descubre el sentido de su vida. Jesús lo realiza en su ministerio y dado que el sentido es simultáneamente la entrega a los suyos y la obediencia al Padre, el espacio privilegiado para esa elaboración-búsqueda es la escucha de la Palabra. Silva cita dos textos bíblicos en esta línea: Lc 24,44 y Lc 11,27-28.

La elaboración-descubrimiento del sentido de la vida para Jesús no basta, es necesario que ese sentido sea también descubierto por sus seguidores. ¿Qué nos dice esto de la relación entre Jesús y su Padre y la relación de los hombres con el Espíritu? El Padre no pide a Jesús ser obedecido sin antes ser conocido, experimentado y comprendido. No hay sentido teológico de la obediencia de Jesús sin horizonte de la voluntad salvífica del Padre: el horizonte de la obediencia es el amor por el Reino de Dios.

Creo que la respuesta va en profunda continuidad con el Dios del éxodo: Dios no pide ser obedecido sin antes ser conocido; el decálogo no comienza con un precepto sino con una palabra que resume la experiencia: "Yo soy el Señor tu Dios que te saqué de la tierra de Egipto, fuera de la casa de servidumbre" (Ex 20,1).

En síntesis, mediante una exploración literaria y teológica del personaje Jesús, Silva presenta una respuesta compleja a la pregunta por el sentido de la muerte de Jesús: sentido que es asesinato y entrega libre por amor al Padre que ama a la humanidad. Este sentido encuentra una continuidad bíblica que impulsa a la reflexión teológica y al diálogo entre sus diversos campos disciplinarios.

\section{Distancia crítica}

Señalo aquí dos elementos con los cuales no me siento demasiado cómodo en la lectura. Intento plantear estos límites tomando en cuenta las mismas pretensiones que el autor enuncia como su marco metodológico.

El autor propone que el lector debe entrar en el mundo que el texto despliega frente a él y en contacto con el cual el lector elabora el sentido del texto. El principio ricoeriano que enuncia implica que se atienda a la particular construcción del relato. En ese marco, el concepto de trama o intriga en relación con el de narrador son cruciales y me parece que han quedado demasiado disimulados en este volumen (no así en el primero) o reducidas a la misma intriga para los cuatro evangelistas. Este déficit plantea el peligro de uniformización o conflación de la 
figura de Jesús. ¿Los cuatro evangelios contestan de la misma forma la pregunta? Poca duda cabe. ¿Los cuatro llevan al lector por el mismo camino? El libro puede apoyar un sí que no es tan rotundo. Este es un peligro que Silva intenta superar indicando las diferencias que se presentan en cada evangelio en los episodios que analiza y por tanto invito a los futuros lectores de este libro a tomar en serio esta intención del autor. Otras dos indicaciones me parecen útiles en esta línea: (1) la lectura conjunta o cercana del volumen primero, que contiene la categoría de "drama"; (2) la segunda indicación puede parecer obvia: el libro se trata de una ayuda para entrar en los evangelios, que la lectura de las páginas no deje al lector solo en el umbral del mundo de los evangelios, sino que se anime a entrar en ellos.

Un segundo límite. Sergio Silva propone una lectura del "Jesús de los evangelios" tratando de navegar fuera de la corriente de las aguas de la exégesis histórica pero aprovechando bastantes de sus resultados. Yo situaría la obra entre las búsquedas de la recuperación de la Biblia entendida como una obra de arte literaria y teológica; lo dice él mismo. En el cuerpo del texto, hay cierto uso del vocabulario utilizado que deja cierto sabor historizante más que literario (p.e.: hechos biográficos, hitos durante el ministerio, etc.). Este vocabulario puede distraer al lector del horizonte trazado para él y entra un poco en el juego señalado por el límite anterior. 